\title{
Using Time Driven-Activity Based Costing TD-ABC approach for controlling
}

\author{
Jaber H. Ali ${ }^{1}$, Doa'a Qahtan² \\ \{drjaber@stu.edu.iq ${ }^{1}$ \} \\ Management Technical College, Southern Technical University, Basra, Iraq ${ }^{1}$ \\ Faculty of Graduate Studies, Southern Technical University, Basra, Iraq ${ }^{2}$
}

\begin{abstract}
The aim of this research to reach the possibility of using TD-ABC approach and its ability to determine unused capacity and actual time of activities, which leads to the effectiveness of the control system. In addition, the Process Mapping (PM) that enhances of controlling the implementation of activities. The research was represented case study in Ibn Majid Co., which still depend on traditional accounting systems. Where contemporary accounting systems have emerged to handling the shortcomings in the traditional systems, and the problems they face and to overcome inaccuracies in calculating product/service costs and allocating indirect costs. The study relied on the approach Time Driven-Activity based costing TD-ABC and its role in the control process by providing accurate information on the actually time on per activity, the costs of exploited resources and the exclusion of unused capacity. The researchers concluded the application of the TD$\mathrm{ABC}$ approach led to the allocation of indirect costs more accurately and relatively, in addition to determining the practical Capacity and determining the time consumed by each activities, which enables the system to control costs and operations.
\end{abstract}

Keywords: Activity Based Costing (ABC), Time Driven-Activity based costing (TDABC), Controlling, Process Mapping (PM).

\section{Introduction:}

The focus has become on the manufacturing of success and continuity, including improving quality, cost reduction, determining real time, constant innovation and other basic demands adopted by economic units to maintain their competitive position in the market. In order to succeed, companies have to react quickly and produce a top quality with low-cost product in appropriate time[1].The companies to manage cost reduction in production processes should preform efficient accounting systems so as to calculate the influnce of refinements on the cost of products, as well as to control costs, Process and this to ensure continuity and development [2]. Traditional cost accounting has received attention, which has led to many methods of calculating it and differing in the way it deals with costs, which are focused mainly on manufacturing costs towards the determination of the manufacturing cost per unit, dynamic cost management approach involves modern managerial accounting methods focused on the total costs through the whole product life cycle [3]. The study significance arise in the importance of the approach Time Driven- activities Based costing TD-ABC, as it is one of the contemporary 
approaches that work to enhance the cost accounting system for the economic unit and provide more accurate information by determining the actual time spent of activities, which affects the effectiveness of the control system [4].The TD-ABC approach emerged to overcome the defects of the activity-based cost approach (ABC) because of the difficulties faced by this approach, especially in terms of the high costs of its application, its need for many data and details, and to solve the problem of imprecise allocation of indirect costs by relying on many cost drivers [5]. Whereas, the TD-ABC approach provides an intact methodology for measuring the cost of companies' products, which helps management in performing its basic functions in controlling and making appropriate decisions, and thus the possibility of evaluating the performance of companies' activities.

\section{2. literature review:}

\subsection{THE TRADITIONAL \& CONTEMPORARY ACCOUNTING SYSTEMS:}

Kaplan \& Cooper 1998 had been analyzed many inserted cost system it listed to grow profitability and performance. which was the traditional costing systems that used at most previously and its no longer in financial reporting procedures. Direct costs in the traditional costing system are attributed directly to the cost objects. In an inversion, indirect costs have been allocated to each cost object using one or a few cost drivers on the basis of volume (ex. direct labor, machine hours, units of production, ...etc) [6]. The traditional costing system has been used (DM, DL \& OH) to assign the cost of product. Nevertheless easy using, traditional costing system hasn't allocated duly overhead costs for various products "average allocation of $\mathrm{OH}$ costs" [7]. Cost systems have attended a several of developments that resulted in a reconsideration of the traditional cost accounting systems, which have been subjected to many criticisms because of the information presented that lacks accuracy and appropriateness in under of the modern environment. In addition, cost-reduction and cost-control activities to improve performance are necessary to warranty profit margins and increasingly as a component of competitiveness of modern economic units, that tended to operate in the global market under strong competition [8]. An approach that distinguish the activities which needed to produce a specific service/product and assigns the cost of each activity resource to operations according to the actual consumption is called activity Activity-Based Costing ABC . it's One of the best tools for refining a costing system, an approach to address indirect costs has refines, and one of the best tools for improving the costing system. The $\mathrm{ABC}$ is allocat cost out of two stages 1) processes consume activities, 2) activities consume costs. Subsequntly the overhead costs of operations were allocated based on the activities consumed within the provision of those services, as the (ABC) approach improves the costing system by identifying individual activities as the primary cost purposes. Because of criticism directed at the traditional costing system, in achieving effective control over indirect costs, in planning and making sound decisions, and in the deceptive results and data shown by the traditional costing system [9] [10]. On the other side, the overhead costs are determined the allocated of the supplied resources costs for activities which based on drivers relevant to those activities. Therefore, the costs of products /services that used a huge amount of activities will be higher than products /services that do not [11]. In 2003-2004 and more comprehensively in 2007, Kaplan \& Anderson reference to the 
main implementing troubles of the traditional $\mathrm{ABC}$ as following:(1)Time consuming and costly were result to the interviewing and surveying process (2)The ABC approch data have been subjective ,complicated to validate and expensive to store, process and report (3) Most ABC approach was local and hadn't provided an completed vision of institution-wide profit opportunities (4)The ABC approach was theoretically incorrect because it preclouded the possiblity for unused capacity [4].

\subsection{TIME DRIVEN- ACTIVITY BASED COSTING (TD-ABC):}

To overcome the difficulties presented in $\mathrm{ABC}$ approach (Kaplan \& Anderson) developed what is called TD-ABC approach [6]. TD-ABC approach can into implemented proportionality speedily because only estimates of two parameters are required: (1) the unit cost of supplying capacity (ex: cost per min.); (2) the time required to perform an activity [9]. TD-ABC approach emulate the actual processes used to perform work throughout a project. It can therefore capture far more difference and complexity than a traditional $\mathrm{ABC}$ approach, without creating an exploding request for storage, data estimates, or processing abilities. Using TD-ABC, a company can adopt complexity rather than being forced to use inaccurate, simplified $\mathrm{ABC}$ models of its complex businesses [12]. Acorn Systems onset workout more delicate with used the time estimates rate $\&$ time equations. An equations have been fed already from Enterprise Resource Planning system (ERP) with information collected from transaction coils [6]. And many researchers have defined TD-ABC's cost approach TD-ABC, the initial of them [12] defined it as "it is a cost estimation approach in which time is the only driven and its purpose is to provide activity costs with the basis of time consumption for each activity." [13] added that TD-ABC is "a modified version of activity-based costing (ABC), a cost accounting approach that relies on employee reported data to determine the percentage of time consume by activities, or on activity time sheet. Existing. Data generated in this way can be time-consuming and expensive to collect as well as difficult to validate." The procedures for applying the TD-ABC approach are the following steps [14], as shown in Fig.1. below:

\begin{tabular}{|c|c|}
\hline & -Identify the various resource groups (departments) \\
\hline & - Estimate the total cost of each resource group \\
\hline step 3 & $\begin{array}{l}\text {-Estimate the practical capacity of each resource group (e.g., available working } \\
\text { hours, excluding vacation, meeting and training hours) }\end{array}$ \\
\hline St & $\begin{array}{l}\text { - Calculate the unit cost of each resource group by dividing the total cost of the } \\
\text { resource group by the practical capacity }\end{array}$ \\
\hline & $\begin{array}{l}\text { - determine the time estimation for each event, based upon the time eqution } \\
\text { for the activity and the charictaries of the event }\end{array}$ \\
\hline & $\begin{array}{l}\text {-Multiply the unit cost of each resource group by the time estimate for the } \\
\text { event. }\end{array}$ \\
\hline
\end{tabular}

Fig.1. Steps of implemention TD-ABC approach

An approach TD-ABC calculates cost by concentricity on two elements:(1) the cost of each unit of time (2) the quantity of time required for each stage or process to be completed [15]. 
Total cost is known as "the cost of all the resources supplied to the process or department" resources such as: personnel, supervision, equipment, infrastructure and technology.Practical capacity is known as "the amount of time employees work non-stop" which represent first parameter is sum by dividing the total cost of supplying the resource capacity by practical capacity [12]. There were two methods to get this a mount: a proportion of theoretical capacity 1) Assuming practical capacity is about $80 \%-85 \%$ to labor (due to rests, arrival and departure, meetings and training) and for machines (due to repair, maintenance and schedule change) with full theoretical capacity, 2) Calculate the adjusted real values of the company and that the accuracy is not objective, because the approximate reilability is enough because critical errors going to be reveal either unexpected excess or in lack of allocated resources [16].

\subsection{THE ROLE OF CONTROLLING FOR TD-ABC APPROACH:}

Controlling pointed out to management efforts to effect the actions of persons in charge of performing functions, afford costs and growing revenue. In this respect, (Robert et al.,1997) considered management as two-stages process: 'planning' indicate to the method that management plans and individuals want to carry out, 'control' indicate to the excutions used to locate whether real performance is consistent with these plans. Meantime management sets the comperhensive aims the company, defines the center of accountability (responsibility) and layout evaluation, reporting procedures and standards [17]. The application of effective methods to support output enformant control plays an important role in the success of each manufacturing system. Without the implementation of sophisticated output performance control system, the prosperite of all productions planning activities is in suspicion. Looking forward to the current status of study in both of them detect the fact that minimal important has been paid to the development of production performance control systems [18]. The Cost Control Systems (CCS) are formated of methods and steps in order to help controlling at the operation costs and ensures that cost dosen't exceed a certain level. Cooper \& Dart in the fileds of Target Costing (TC) and value analysis, Activity Based Costing (ABC), Time Driven- Activity based costing (TD-ABC) . All of these approaches are driven to controlling a enterprise cost to improve firm performance. These processes have been systematized became an inserted (CCS). Enterprise performance reflects the cumulative result of efforts of a firm, it has transfred different understanding to various individuals. That Resulting to convey from financial (conventional) to non financial (Contemporary) measures of performance, The non-financial part measured was on customer value "the difference between realization and sacrifice" in idioms of lead time to delivery and defect or reduction level and market share [19] [20]. The TD-ABC approach provides accurate information about the real time, cost of the actual resources consumed for each activity, as well as assist allocate indirect costs on products/ services based on the time driven and provides the necessary measures of the exploited and unutilized production capacity for each activity, as it works to determine a more equitable and objective product cost which serves as a control tool to determine the implementation process in real time using time equations and the process mapping of the TD-ABC approach can be used as a controlling tool to track the implementation of strategies [13]. Process Mapping (PM) is a explain for an analysis of the process flow by display between how did work do and how had did it, jobs of the system must be perform from how does the system build to perform those substantial functions since received the order to delivery it the customer [21]. The Process Map (PM) determins for each stage of the project process. In any stage, the time required to do each activity is estimated. Then, the required resource costs for each stage is calculated by assignment the cost for per unit capacity [22]. 
Afterwards, having the knowlge in the intended field of work and the results to be obtained, we are identifing activities to be performed and the facilities to be utilized to producting the suggested result for the project. Then we draw the (PM) of activities identify their dependencies, and estimated actual time, resources and time restriction. After that, the operational budget is evolved, determining the (direct \& indirect) costs, founding the base plan to monitoring and controlling the output process [23].

\section{Methodology:}

Study Problem: In light of the increasing competition in the markets, companies seek to adopt firm accounting systems, as they are one of the most important systems that produce the necessary information that helps management to take the necessary decisions and enable the control system. Therefore, it should always aim to keeping effective cost systems to ensure the company's continuity in the market. Where the problem of the study is that the case study company adopts traditional cost accounting systems based on actual costs that do not take into account the factors of time and theoretical capacity or reduce costs. Which leads to bearing the product at relatively high costs that negatively affect competitiveness in the market and limited the process of controlling costs and operations operational. The study problem is framing with the following questions: (1) what is the importance of applying the TD-ABC approach in determining the actual time of activities, which contributes to accurate cost calculation? (2) Does the use of the TD-ABC approach help identify the unused capacity, which helps the effectiveness of the control system for production processes?

Study Hypothesis: The study was based on a main hypothesis that: (The use of the approach TD-ABC enables the system of control on costs and activities by determining the real time consumed of each activities and unused capacity, which enhances the process of cost control).

Study data collection: To raise data and information for realize the theoretical and practical side of the study the researcher was adopted on books and articles that dealt with research variables, in addition documents, records, and official reports of the case study that were collected directly or indirectly through unstructured visits and interviews, as well benefiting from some of the basic observations that crystallized during the discussion with Engineers and project administrators for the company beneath study.

Study methods: It relied on the inductive and deductive approach in achieving the objectives of the study. The following equations Table 1. were using to reach the results that would address the problem of the study and achieve appropriate control over activities [24] [1] [4] [11].

Table 1.Equations of the application case Study by using TD-ABC

$\mathrm{AR}=$ Capacity cost rate $=\frac{\text { Cost of all resources supplied }}{\mathrm{Tt}} \ldots \ldots \ldots(1)$
$\begin{gathered}\text { Phere } \\ \mathrm{Tt}\end{gathered}$
$\mathrm{Tt}=$ Time must to perform an activity per Min.
$\beta 0=$ The standard time to perform the basic activity per Min.
$\beta \mathrm{i}=$ The estimated time to perform the incremental activity per Min.


$\mathrm{Xi}=$ The quantity of incremental activity (Time).

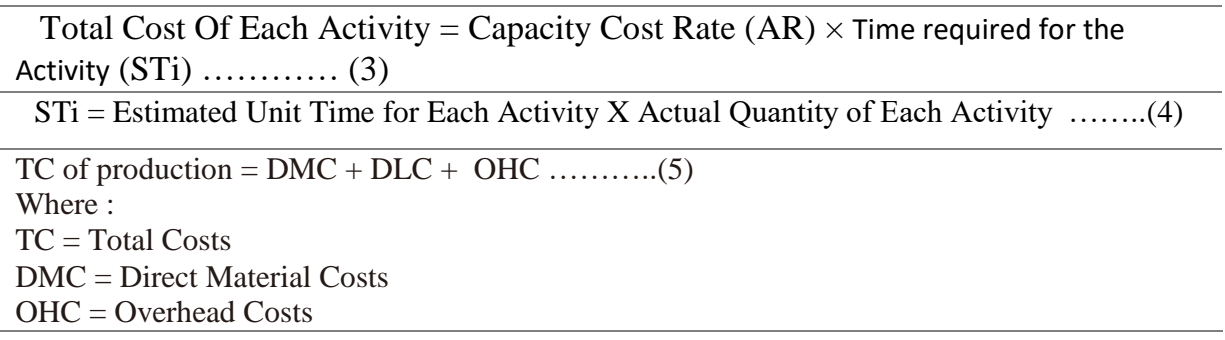

\section{Previous Studies:}

A study [25] entitled: "Development of a real-time TDABC model for production activities A case study at a manufacturing company". The study aimed to clarification the influence of utiliza the TD-ABC approach precise real-time production activity data rather than estimated values or direct observation. The study rely on the deductive and inductive approach, the study sample was conducted as a case study at the Swedish startup battery manufacturing company Northvolt, and the data were collected by conducting 8 irregular interviews with different employees within the company under study. The results of the study show that TD-ABC approach with components of automated activities directly refer to the production cost accounting is automated, and this means that when a cost is applied to a cost object through this apprach, this cost is calculated automatically and accurately in the system. It is not necessary to update the production cost for each product. Retrospectively or randomly calculated but automatically calculated in real time. The study recommends that exploring the necessary data that enhances the traceability of activities, as the resources to perform activities consist of materials for cost purposes for the resources they consume, which contribute to supporting automated management. A study [1] entitled: "TDABC for a manufacturing environment: A case study" This study aimed to Implementation of TD-ABC in a furniture manufacturing company to estimate product costing and compare the cost obtained from TDABC with the traditional costing system. As well as the management, effect of TDABC in a small manufacturing environment. The results of the study showed the TDABC system assistances the directors, department bosses to differentiate, and analyzing the implicit activities that drive the overhead costs. This model also identifies the operational improvement, to help the company to diminishing the cost of the production. The study recommended the application of TDABC in small manufacturing industries as it helps to discuss the results and its usefulness in small scale manufacturing industries. It provides useful information for making decisions about future investment and expansion of the manufacturing setup. A study [26] entitled " The Impact of Applying Time Driven Activity-Based Costing on Improving the Efficiency of Performance in Jordanian Industrial Corporations: A Survey Study". The study aimed to display the importance of applying TD-ABC approach to improving performance efficiency in Jordanian industrial companies by using the descriptive analytical method. A survey list has been prepared; the data collected and processed to a sample of 73 participants in different management positions from 30 industrial companies listed on the Amman Stock Exchange (ASE). The survey analyzed by using SPSS program. The results of the study refer to the company that applied TD-ABC approach benefited of technological developments based on activity diagrams and its ability to help management see the whole view of the activities' performance and evaluate the company's competitive strategy, which was reflected in improving pricing decisions for different products. The study recommends the necessity of applying TD-ABC in companies as it has proven its effect on reducing product costs and increasing corporate profitability through industrial companies' activities plans. A study [5] entitled "Application of the TDABC Model in the Logistics Process Using Different Capacity Cost Rates". The study aimed to design and application (TD-ABC) technology for the logistics process using different capacity cost rates, and aims to description and analysis detail of the resources economic unit, its activities and cost objects that constitute the logistics process in order to develop an appropriate model of TD-ABC. The results of the study using the TD-ABC approach helps to 
adequately reflect the logistic function and these activities have specific resources allocated and can be measured by different outputs because it is supported by a string of time equations. The study recommends the TD-ABC model developed in this case study can used in similar cases and as a basis for analysis of logistics costs in other logistics operations. Moreover, managers can depend on the proposed approach to analyze product profitability and logistics cost structure.

\section{THE APPLICATION OF TD-ABC APPROACH:}

Ibn Majid Company is a leading company in heavy engineering industries, especially the manufacture and installation of oil and industrial equipment that meets the needs of the companies of the Ministry of Oil, Industry, Electricity and the private sector of these products. A case study began by collecting data related to the pipelining project within the company, recording notes about the stages of the production process and the timing of each phase, in addition to data related to machinery and equipment, their depreciation, cost of consumed DM, $\mathrm{DL}$ and all $\mathrm{OH}$. After collecting the data, a process flow chart was created to provide an overview of the production stages of the company under study, as shown in Fig. 2. below:

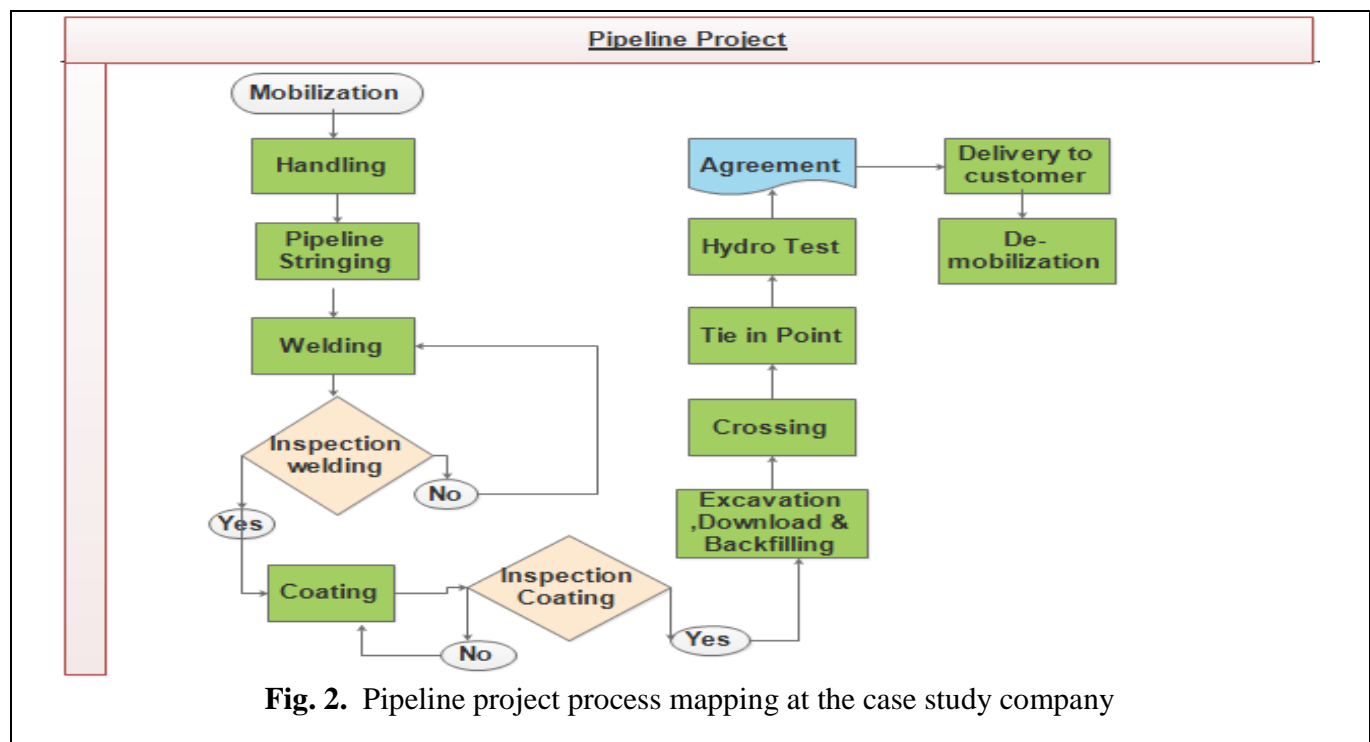

To calculate costs using the TD-ABC approach, there are steps that must be followed, starting with the activities being determined ,then estimated the costs of whole resources utilized, and the accepted theoretical Capacity to calculate the Capacity cost rate, Time equation must established for every activity, after that estimated time is determined. per activity, the Total Cost (TC) is determined, as follows:

5.1 Production activities used: The first step taken with the TD-ABC approach is analyze and locate the industrialization activities that occur, in order that comprehend their area and the specific series of events occurring, for whole actions differ however, it has the same purpose. At Ibn Majid State CO. for a case study of the piping project, the activities are 
represented by (Mobilization, Handling, Pipeline Stringing, welding, Inspection welding including "visual and x-ray inspection", coating process, the process of drilling, Excavation -Download \& Backfilling, Crossing, Tie in points, hydro- test, and Demobilization). The project was handed over to the beneficiary under the supervision of the project manager, site engineer and others, and then an order was issued. Raise the work site represented by equipped office caravans and their accessories, in addition to machines and other equipment.

5.2 Estimated Total Cost (TC) of the resources utilized: If the all resources utilized gradient beneath the similar activities, the costs can assigned to the activity directly. Nevertheless, if the resources are utilized for multiple activities, an apportionment method based the suitable cost driver should use. In this research, resources are assign based on the kinds of resources utilized for per activity, and they are divided to (labor wage, equipment \& machinery costs, depreciations, training and qualification costs, and other costs). As shown in Table 2.

Table 2. Statement of resource supplied

\begin{tabular}{|c|c|c|c|c|}
\hline No. & Activity & $\begin{array}{l}\text { Direct Labor } \\
\text { (IQD) }\end{array}$ & $\begin{array}{c}\text { Factory Overhead } \\
\text { (IQD) }\end{array}$ & $\begin{array}{l}\text { cost of all resource } \\
\text { supplied (IQD) }\end{array}$ \\
\hline 1 & Mobilization & $3,350,000.000$ & $18,758,055.556$ & $22,108,055.556$ \\
\hline 2 & Handling & $5,950,000.000$ & $6,500,000.000$ & $12,450,000.000$ \\
\hline 3 & Pipeline Stringing & $5,860,000.000$ & $1,200,000.000$ & $7,060,000.000$ \\
\hline 4 & Welding & $651,424,000.000$ & $83,775,000.000$ & $735,199,000.000$ \\
\hline 5 & $\begin{array}{c}\text { Inspection welding (Visual, } \\
\text { X-ray) }\end{array}$ & $4,750,000.000$ & $81,000,000.000$ & $85,750,000.000$ \\
\hline 6 & Coating & $23,700,000.000$ & $8,250,000.000$ & $31,950,000.000$ \\
\hline 7 & $\begin{array}{c}\text { Excavation, Download \& } \\
\text { Backfilling }\end{array}$ & $6,250,000.000$ & $2,600,000.000$ & $8,850,000.000$ \\
\hline 8 & Crossing & $4,900,000.000$ & $1,430,000.000$ & $6,330,000.000$ \\
\hline 9 & Tie in Point & $2,600,000.000$ & $1,335,000.000$ & $3,935,000.000$ \\
\hline 10 & Hydro Test & $5,500,000.000$ & $900,000.000$ & $6,400,000.000$ \\
\hline \multirow[t]{2}{*}{11} & Demobilization & $1,150,000.000$ & $1,958,055.556$ & $3,108,055.556$ \\
\hline & Total & $715,434,000.000$ & $207,706,111.111$ & $923,140,111.111$ \\
\hline
\end{tabular}

5.3 Estimated practical capacity (acceptable cap.): Hours of project working inside the site it take 6 days in a week, from 7 a.m. to 3 p.m. The employees are working an average 8 hours a day, and 250 days a year. $20 \%$ is a rate of these deductions for breaks, training and maintenance of these working hours, this mean the employees have a practical cap. Of 96,000.00 minutes per a year.

5.4 Calculation of the capacity cost rates: In this step, the unit cost rate was calculated for the time required to perform each activity of the project. This value is obtained by dividing 
the estimated total cost of each activity the conversion cost (direct labor costs and overhead costs) specified in the first step by the process capacity specified in step previous .The cap. Cost rate (per minute) able to acquire using the following equation (1).

$$
\mathrm{AR}=\text { Capacity cost rate }=\frac{\text { Cost of all resources supplied }}{\text { Practical capacity }}
$$

Table 3. Illustrate summary of the Cap. cost rate of each activity for pipeline project activity.

\begin{tabular}{|c|c|c|c|c|}
\hline No. & Activity & $\begin{array}{c}\text { cost of all resource } \\
\text { supplied }\end{array}$ & $\begin{array}{l}\text { Practical Capacity } \\
\text { supplied } \mathrm{min} / \mathrm{Y}\end{array}$ & $\begin{array}{l}\text { Capacity Cost } \\
\text { Rate (IQD/min) }\end{array}$ \\
\hline 1 & Mobilization & $22,108,055.556$ & 96,000 & 206.334 \\
\hline 2 & Handling & $12,450,000.000$ & 96,000 & 98.438 \\
\hline 3 & Pipeline Stringing & $7,060,000.000$ & 96,000 & 52.708 \\
\hline 4 & Welding & $735,199,000.000$ & 96,000 & $7,798.948$ \\
\hline 5 & Inspection welding & $85,750,000.000$ & 96,000 & 934.896 \\
\hline 6 & Coating & $31,950,000.000$ & 96,000 & 289.063 \\
\hline 8 & $\begin{array}{c}\text { Excavation, Download } \\
\text { \& Backfilling }\end{array}$ & $8,850,000.000$ & 96,000 & 81.771 \\
\hline 9 & Crossing & $6,330,000.000$ & 96,000 & 55.521 \\
\hline 10 & Tie in Point & $3,935,000.000$ & 96,000 & 20.156 \\
\hline 11 & Hydro Test & $6,400,000.000$ & 96,000 & 56.250 \\
\hline \multirow[t]{2}{*}{12} & Demobilization & $3,108,055.556$ & 96,000 & 21.959 \\
\hline & Total & $923,140,111.111$ & & \\
\hline
\end{tabular}

Table 3. Cap. Cost Rate

5.5 Activity time equation: TD-ABC time equation can combine all the time needed to undertake all activities in each activity within a single equation, and the mathematical model used to establish TD-ABC time equation is shown below equation (2):

Where:

$$
\mathbf{T t}=\boldsymbol{\beta} 0+\beta \mathbf{i X}
$$

$\mathrm{Tt}=$ Time must to perform an activity per Min.

$\beta 0=$ The standard time to perform the basic activity per Min.

$\beta \mathrm{i}=$ The estimated time to perform the incremental activity per Min.

$\mathrm{Xi}=$ The quantity of incremental activity (Time).

5.6 Determination of the estimated time for each activity: A time equation was needed to develop to calculate the estimated production time. The estimated time for each activity 
was determined based on the Motion and Time study principles. As shown in Table 4. , Time required for each Activity defined in Table 5.

Table 4. Volume of cost-drivers for the project Pipe line

\begin{tabular}{|c|c|c|c|}
\hline Var. & Activity & Driver & $\begin{array}{l}\text { Quantity (per day } \\
\text { for } 1 \text { groups) }\end{array}$ \\
\hline $\mathrm{X} 1$ & Mobilization & No. of round & 1 \\
\hline $\mathrm{X} 2$ & Handling & No. of round & 1 \\
\hline $\mathrm{X} 3$ & Pipeline Stringing & $\mathrm{km}$ & 1 \\
\hline $\mathrm{X} 4$ & Welding & No. of joint & 8 \\
\hline $\mathrm{X} 5$ & Inspection welding & No. of sample joint & 5 \\
\hline X6 & Coating & No. of round & 5 \\
\hline $\mathrm{X} 7$ & $\begin{array}{c}\text { Excavation ,Download } \\
\text { \& Backfilling }\end{array}$ & $\mathrm{km}$ & 1 \\
\hline $\mathrm{X} 8$ & Crossing & No. of Gross & 2 \\
\hline X9 & Tie in Point & No. of point & 2 \\
\hline $\mathrm{X} 10$ & Hydro Test & $\mathrm{km}$ & 5 \\
\hline $\mathrm{X} 11$ & Demobilization & No. of round & 1 \\
\hline
\end{tabular}

Table 5.Time estimated for each Activities

\begin{tabular}{|c|c|c|c|c|c|c|}
\hline No. & Activity & $\begin{array}{c}\text { No. of } \\
\text { Work } \\
\text { days (1) }\end{array}$ & $\begin{array}{c}\text { Quantity } \\
(2)\end{array}$ & $\begin{array}{c}\text { Available capacity } \\
\text { per minute } \\
(3)=(1) *\left(8 H^{*} 60\right. \\
\text { min })\end{array}$ & $\begin{array}{c}\text { practical } \\
\text { capacity (min) } \\
(4)=(3) * 80 \%\end{array}$ & $\begin{array}{c}\text { Time required } \\
\text { for the Activity } \\
(5)=(4) *(1)\end{array}$ \\
\hline 1 & Mobilization & 15 & 1 & $7,200.00$ & $5,760.00$ & $5,760.00$ \\
2 & Handling & 20 & 1 & $9,600.00$ & $7,680.00$ & $7,680.00$ \\
3 & Pipeline Stringing & 25 & 1 & $12,000.00$ & $9,600.00$ & $9,600.00$ \\
4 & Welding & 35 & 8 & $16,800.00$ & $13,440.00$ & $107,520.00$ \\
5 & $\begin{array}{c}\text { Inspection welding } \\
\text { (Visual X-ray) }\end{array}$ & 25 & 5 & $12,000.00$ & $9,600.00$ & $48,000.00$ \\
6 & $\begin{array}{c}\text { Coating } \\
\text { Excavation }\end{array}$ & 30 & 5 & $14,400.00$ & $11,520.00$ & $57,600.00$ \\
7 & $\begin{array}{l}\text { Download \& } \\
\text { Backfilling }\end{array}$ & 30 & 1 & $14,400.00$ & $11,520.00$ & $11,520.00$ \\
\end{tabular}




\begin{tabular}{|ccccccc}
8 & Crossing & 15 & 2 & $7,200.00$ & $5,760.00$ & $11,520.00$ \\
9 & Tie in Point & 15 & 2 & $7,200.00$ & $5,760.00$ & $11,520.00$ \\
10 & Hydro Test & 25 & 5 & $12,000.00$ & $9,600.00$ & $48,000.00$ \\
11 & Demobilization & 15 & 1 & $7,200.00$ & $5,760.00$ & $5,760.00$ \\
\hline & Total & 250 & & $120,000.00$ & & $324,480.00$ \\
\hline
\end{tabular}

5.7 Calculation of cost per product unit (unit cost):

Total Cost Of Each Activity = Capacity Cost Rate $(A R) \times$ Time required for the Activity (STi)

(3)

Cost of all resources supplied

$\mathrm{AR}=$ Capacity Cost Rate

$$
\text { Practical Capacity of Resources Supplied }
$$

STi = Estimated Unit Time for Each Activity X Actual Quantity of Each Activity (4)

Table 6.Calculate the Total Conversion costs of each activity

\begin{tabular}{|c|c|c|c|c|c|c|}
\hline No. & Activity & $\begin{array}{l}\text { Time } \\
\text { Driven } \\
(1)\end{array}$ & $\begin{array}{l}\text { Time required } \\
\text { for the Act. } \\
\text { Sti (min) (2) }\end{array}$ & $\begin{array}{c}\text { Cap. Cost } \\
\text { Rate(AR) } \\
\text { (3) }\end{array}$ & $\begin{array}{l}\text { TC Of Each Act.(4) } \\
=\operatorname{AR}(3) \times \operatorname{Sti}(2)\end{array}$ & $\begin{array}{l}\text { Allocating costs } \\
\text { unit to each } \\
\text { activity } \\
(5)=(4) /(1)\end{array}$ \\
\hline 1 & Mobilization & 1 & $5,760.00$ & 230.29 & $1,326,483.333$ & $1,326,483.333$ \\
\hline 2 & Handling & 1 & $7,680.00$ & 129.69 & $996,000.000$ & $996,000.000$ \\
\hline 3 & Pipeline Stringing & 1 & $9,600.00$ & 73.54 & $706,000.000$ & $706,000.000$ \\
\hline 4 & Welding & 8 & $107,520.00$ & $7,658.32$ & $823,422,880.000$ & $102,927,860.000$ \\
\hline 5 & $\begin{array}{l}\text { Inspection welding } \\
\text { (Visual, X-ray) }\end{array}$ & 5 & $48,000.00$ & 893.23 & $42,875,000.000$ & $8,575,000.000$ \\
\hline 6 & Coating & 5 & $57,600.00$ & 332.81 & $19,170,000.000$ & $3,834,000.000$ \\
\hline 8 & $\begin{array}{l}\text { Excavation, } \\
\text { Download \& } \\
\text { Backfilling }\end{array}$ & 1 & $11,520.00$ & 92.19 & $1,062,000.000$ & $1,062,000.000$ \\
\hline 9 & Crossing & 2 & $11,520.00$ & 65.94 & $759,600.000$ & $379,800.000$ \\
\hline 10 & Tie in Point & 2 & $11,520.00$ & 40.99 & $472,200.000$ & $236,100.000$ \\
\hline 11 & Hydro Test & 5 & $48,000.00$ & 66.67 & $3,200,000.000$ & $640,000.000$ \\
\hline 12 & Demobilization & 1 & $5,760.00$ & 32.38 & $186,483.333$ & $186,483.333$ \\
\hline & $\begin{array}{l}\text { Total Conversion } \\
\text { costs (IQD) }\end{array}$ & & & & $894,176,646.667$ & $120,869,726.667$ \\
\hline
\end{tabular}

5.8 The total cost of production: able to obtain through the equation below:

$\mathrm{TC}$ of project $=\mathrm{DMC}+\mathrm{DLC}+\mathrm{OHC}$

Where : 
$\mathrm{TC}=$ Total Costs

$\mathrm{CDM}=$ Direct Material Costs

$\mathrm{OHC}=$ Overhead Costs

TC of Pipeline project $=45,696,000.000+894,176,646.667=939,872,646.667 \mathrm{IQD}$

\section{RESULTS AND DISCUSSION:}

TD-ABC provides the detailed analysis of the cost. From the above data, it can be seen that The TD-ABC approach using the process mapping Fig.1. Helps to define the steps of the pipelining project and the sequence of operations, thus enhancing the process of controlling the implementation. It is noted that the utilize of resources for various activities as seen (Table 2.), the resources were assigned depend on the kind of resources utilized for each activity. Which achieves the process of controlling the consumed resources and allocating them to activities in a real and fair manner, leading to a more accurate calculation of the cost of project. The TD$\mathrm{ABC}$ approach using in allocating the indirect costs represented as wages (transportation, training, qualification, safety courses. etc.) by calculating the capacity cost rate as see (Table 3.) by using Equation (1). The total actual indirect costs lead about to a reduction the indirect costs and the unit cost of each activity as see (Table 6.)by using Equation (3) and (4), which support management in controlling costs leads to an improve Profitability. TD-ABC is using time as the cost driver. Therefore, more production time is responsible for the higher cost. The time of the activity is estimated using Time Equations (see Table 4.).It indicated that the time consumed by activity is based on the (No. of round, No. of gross, No. of Tie in point, KM, etc.). The production help managers can control on parameters of activities to reduce the time and the cost. In this way, it helps the management to identify the waste in manufacturing that causes high production time and high manufacturing cost. The TD-ABC approach was related to the time equation as see (Table 5.) the Time estimated for each Activities by using Equation (2). Which provides detailed and clear information to the management about the distribution of time on activities and the identification of activities that consume more time, in addition to making decisions related to reducing time, which is reflected on production processes, which are necessary for the control process and the provision of cost information. Direct Labor is relatively high as see (Table 2.), and this appears especially during welding activities because the company case study relies on daily wage employees from outside the company because there are no specialized employees with experience and certificates of competency in accordance with the Welding Procedure Specification WPS required within the contract. Therefor the researcher recommends Employees Designation Specialized experienced and efficient to for reduce activities that consume high costs. The cost of raw materials (for pipeline project represent the low amount because the Customer supplied Pipes with fittings, this, in turn, reduces the inventory space within the company case study, and reduces waste of raw materials and exposure to spoilage during storage. That cost of raw materials represents the raw materials consumed and supporting the production process such as (welding wire -cutting stone -lifting pods ... etc.).That were provided from the local markets in quantities that suit the needs of the work, which leads to a reduction in the cost of preparing resources compared to foreign markets and reducing the period Import and processing which are non-value-adding activities.

This research provides a contribution to the TD-ABC literature by developing an integrated framework. That expands understanding of how TD-ABC contribute to the allocation of indirect costs more accurately and relatively, in addition to determining the practical capacity and 
determining the time consumed by each activity, unlike previous studies that were limited to studying the impact of one variable of the current study. On the other hand, the practical contributions involve The application of the case study helps the practitioners and administrators of the company under study to reconsider the method of calculating costs and enhance control over unit costs and production processes.

\section{CONCLUTION:}

With growing of industry and rising competition in the manufacturing environment, companies are developing cost accounting systems accompanied with effective control systems to provide feedback of data (financial and non-financial) that are relevant and objective which helps the management in making the necessary decisions to keeping market share. TD-ABC be the substitutional tool for administration to utlized for competence non-HR and HR management and to Improving the process of cost control and operational control. In light of the results obtained, the researchers concluded that the use of the TD-ABC approach in the case study of Ibn Majid Company contributed to the control process, with time equations that led to determining the actual time of activities, and the effect of the consumed resources and time for each activity. According to these result that administrator will control of the real cost driver such as direct material,mostly which is the cost driver for the cost of resources and the activity that consumes the highest cost, as direct labor appeared relatively high, especially during welding activities due the case study's company of dependence on daily wage workers. Wherefore researchers recommend training or hiring competent, experienced and particular worker to perform work efficiently to reduce cost- consuming activities. In addition, the researchers concluded that the non-financial information provided by the TD-ABC approach by determine practical capacity (for workers and machines) and excluding unused capacity enhances operational control for production processes. Based on the previous conclusions, the researchers recommend the need for the company to embrace contemporary accounting methods, the most important of which is the Time Driven- activity based costing (TD-ABC) and it's easy to implement, which provides information that helps management in controlling. In addition, the need to educate companies about the TDABC approach to solve the problem of allocating indirect costs better and distributing them more equitably, as well as to overcome the disadvantages of the traditional method based on time equations. These conclusions confirm the validity of the study hypothesis.

\section{References:}

[1] Ganorkar, Ashwin B., Ramesh R. Lakhe, and Kamalkishor N. Agrawal. "TDABC for a manufacturing environment: A case study." Tékhne 16.2 (2018): 2-10.

[2] ALDANIYAZOV, Korkembay. "Factors and Ways to Reduce Product Costs." Espacios 38.46 (2017): 37-37.

[3] Perčević, Hrvoje, and Mirjana Hladika. "Movement from traditional to modern cost accounting methods in manufacturing companies." Muhasebe ve Finans Tarihi Araştırmaları Dergisi 10 (2016): 155-180.

[4] Namazi, Mohammad. "Time Driven Activity Based Costing: Theory, Applications and Limitations." Iranian Journal of Management Studies 9.3 (2016): 457-482. 
[5] Afonso, Paulo, and Alex Santana. "Application of the TDABC model in the logistics process using different capacity cost rates." Journal of Industrial Engineering and Management (JIEM) 9.5 (2016): 1003-1019.

[6] Guzman, Lorena Siguenza, Alexandra Van den Abbeele, Joos Vandewalle, Henri Verhaaren and Dirk Cattrysse" Recent evolutions in costing systems: A literature review of Time-Driven Activity-Based Costing." Review of Business and Economic Literature 58.1 (2013): 34-64.

[7] Alami \& ElMaraghy, Darwish, and Waguih . "Traditional and Activity Based Aggregate Job Costing Model." Procedia CIRP 93 (2020): 610-615.

[8] Santana, Alex, and Paulo Afonso. "Analysis of Studies on Time-Driven Activity Based Costing (TDABC)." The International Journal of Management Science and Information Technology (IJMSIT) 15 (2015): 133-157.

[9] Akhavan, Sina, Lorrayne Ward, and Kevin J. Bozic. "Time-driven activity-based costing more accurately reflects costs in arthroplasty surgery." Clinical Orthopaedics and Related Research ${ }^{\circledR} 474.1$ (2016): 8-15.

[10] Horngren ,Datar, Srikant M., and Madhav V. Rajan. Horngren's cost accounting: a managerial emphasis. Pearson, 2018.

[11] Ramida, P. O. N. G. W. A. S. I. T., and CHOMPU-INWAI Rungchat. "Analysis of wooden toy manufacturing costs through the application of a time-driven activity-based costing system." Vol. 65, presented at the Symposium on Mechanical Engineering, Industrial Engineering, and Robotics. 2015.

[12] Kaplan, Robert S., and Steven R. Anderson. Time-driven activity-based costing: a simpler and more powerful path to higher profits. Harvard business press, 2007.

[13] Cidav Zuleyha, David Mandell , Jeffrey Pyne, Rinad Beidas, Geoffrey Curran and Steven Marcus:"A pragmatic method for costing implementation strategies using timedriven activity-based costing." Implementation Science 15 (2020): 1-15.

[14] Din ,Kakrona ,Duangpun Kritchanchai,Atchara Dokkulab "Time Driven Activity Based Costing in Outpatient Logistics" , Proceedings of the International Conference on Industrial Engineering and Operations Management Bangkok, Thailand, March 5-7, 2019.

[15] Koolmees, Dylan, et al. "Time-Driven Activity-based Costing for Anterior Cruciate Ligament Reconstruction: A Comparison to Traditional Accounting Methods." Arthroscopy, sports medicine, and rehabilitation 3.1 (2021): e39-e45.

[16] Yonpae ,Park, Yonpae, Sungwoo Jung, and Yousef Jahmani. "Time-Driven ActivityBased Costing Systems for Marketing Decisions." Studies in business and economics 14.1 (2019): 191-207, DOI 10.2478/sbe-2019-0015.

[17] LAWYER, CHUKWUMA OBARA (PhD), “Cost Control and Accountability for Effective Budget Implementation ",SENIOR LECTURER / HEAD, DEPARTMENT OF ACCOUNTANCY, RIVERS STATE UNIVERSITY OF SCIENCE AND TECHNOLOGY PORT HARCOURT.5.21 (2014): 199-202.

[18] Zohoori et al. ,Bahareh Zohoori, Alexander Verbraeck, Morteza Bagherpour \& Masoud Khakdaman,"Monitoring production time and cost performance by combining earned value analysis and adaptive fuzzy control." Computers \& Industrial Engineering 127 (2019): 805-821. https://doi.org/10.1016/j.cie.2018.11.019

[19] Mutya ,Tomasi Mutya, "Cost Control: A Fundamental Tool towards Organisation Performance", Department of Business and Management Studies, Kumi University, Kumi, Uganda, Journal of Accounting \& Marketing ,Journal of Accounting \& Marketing ,ISSN: 2168-9601 Mutya, J Account Mark 2018, 7:3 ,DOI:10.4172/21689601.1000283. 
[20] Cooper \& Dart , Philip C. \& Eleanor D.,"Change in the Management Accountant's Role: Drivers and Diversity",University of Bath, School of Management, Working Paper Series ,Bath (2009).

[21] Nyemba \& Mbohwa, Wilson R., and Charles . "Process mapping and optimization of the process flows of a furniture manufacturing company in Zimbabwe using machine distance matrices." Procedia Manufacturing 8 (2017): 447-454.

[22] Anzai, Yoshimi, "Dissecting costs of CT study: application of TDABC (time-driven activity-based costing) in a tertiary academic center." Academic radiology 24.2 (2017): 200-208. http://dx.doi.org/10.1016/i.acra.2016.11.001

[23] Oliveira ,Rosário Oliveira :"Monitoring and Control of Schedule and Cost

Performance in Facade Conservation",First International Symposium on Risk and Safety of Complex Structures and Components, Department of Civil Engineering, School of Engineering, Polytechnic of Porto, 4200-485 Porto, Portugal 2019.

[24] Ostadi, Bakhtiar, Reza Mokhtarian Daloie, and Mohammad Mehdi Sepehri. "A combined modelling of fuzzy logic and Time-Driven Activity-based Costing (TDABC) for hospital services costing under uncertainty." Journal of biomedical informatics 89 (2019): 11-28.

[25] Rude, Hampus, and Aleksandar Balicevac. "Development of a real-time TDABC model for production activities: A case study at a manufacturing company." (2019). [26] Al-Halabi, Nabil Bashir, and Yazan Mjahed Al-Mnadheh. "The Impact of Applying Time Driven Activity-Based Costing on Improving the Efficiency of Performance in Jordanian Industrial Corporations: A Survey Study." International Journal of Economics and Finance 9.12 (2017): 24-31. 